\title{
Detailed phylogeny of ammonia-oxidizing bacteria determined by rDNA sequences and DNA homology values
}

\footnotetext{
1 Laboratory of Microbial Gene Technology, Department of Chemistry and Biotechnology, Agricultural University of Norway, PO Box 5051, $\mathrm{N}-1432$ Às, Norway

2 Institut für Allgemeine Botanik, Abteilung Mikrobiologie, Universität Hamburg, Ohnhorststrasse 18, D-22609 Hamburg, Germany
}

\author{
Ågot Aakra, ${ }^{1}$ Janne B. Utåker, ${ }^{1}$ Andreas Pommerening-Röser, ${ }^{2}$ \\ Hans-Peter Koops ${ }^{2}$ and Ingolf F. Nes ${ }^{1}$
}

\author{
Author for correspondence: Ågot Aakra. Tel: +47 6494 9456. Fax: +4764941465. \\ e-mail: agot.aakra@ikb.nlh.no
}

\begin{abstract}
A comparison of the phylogeny of 38 isolates of chemolithoautotrophic ammonia-oxidizing bacteria (AOB) based on 16S rRNA gene sequences, 16S-23S rDNA intergenic spacer region (ISR) sequences and species affiliations based on DNA homology values was performed. The organisms studied all belong to the $\beta$-subclass of the Proteobacteria and included representatives of Nitrosomonas, Nitrosococcus and Nitrosospira. The similarity values of the 16S rDNA sequences were high, particularly within the Nitrosospira genus, and based on these sequences it is difficult to determine the phylogenetic position of some AOB. As an alternative and supplement to 16S rRNA gene sequencing, the ISR was sequenced and analysed phylogenetically. Due to considerably lower similarity values, the ISR-based phylogeny gives a better resolution than the phylogeny based on the functional 16S rRNA gene. Since the ISR-based phylogeny of AOB is highly consistent with the 165 rDNA based phylogeny, ISR sequencing appears as a suitable tool for resolving the detailed phylogeny of AOB. The phylogenetic position of two isolates of the former genus 'Nitrosolobus' (now included in the Nitrosospira genus) is not clear. These organisms are close relatives of the former Nitrosospira spp. and 'Nitrosovibrio' spp. (now Nitrosospira), but based on their marginal positions in the phylogenetic trees, DNA-DNA hybridization data and phenotypic characteristics, it is suggested that 'Nitrosolobus' should be a separate genus. DNA homology determination of 11 Nitrosospira isolates revealed two new species of Nitrosospira. The phylogeny of AOB reflected in the trees based on the rDNA sequences is consistent with the species affiliations of AOB by DNA homology values. This observation will probably be important for the interpretation of results from studies of natural diversity of AOB.
\end{abstract}

Keywords: chemolithoautotrophic ammonia-oxidizing bacteria, phylogeny, species determination

\section{INTRODUCTION}

With the exception of two marine species, all known chemolithoautotrophic ammonia-oxidizing bacteria (AOB) constitute a monophyletic group within the $\beta$ -

Abbreviations: $A O B$, chemolithoautotrophic ammonia-oxidizing bacteria; ISR, 16S-23S rDNA intergenic spacer region.

The GenBank/EMBL/DDBJ accession numbers for the 16S rDNA and ISR sequences determined in this study are AJ298724, AJ298725, AJ298728AJ298730, AJ298732-AJ298739, AJ298741-AJ298747 (16S rDNA) and AJ298749-AJ298774 (ISR). subclass of the Proteobacteria. Over the last few years, the phylogeny of $\mathrm{AOB}$ based on $16 \mathrm{~S}$ rDNA sequences has been studied, resulting in reclassification. Based on $16 \mathrm{~S}$ rDNA sequence similarities, the three previously recognized genera 'Nitrosolobus', Nitrosospira and 'Nitrosovibrio' were combined into one genus, Nitrosospira (Head et al., 1993, 1995). 16S rRNA gene sequence information has made it possible to design specific oligonucleotides for the direct monitoring of various subgroups of $\mathrm{AOB}$ in the environment (McCaig et al., 1994; Utåker \& Nes, 1998). The use of these specific oligonucleotides along with activity 
measurements have concluded that the diversity of $\mathrm{AOB}$ in the environment is high and that species other than Nitrosomonas spp. contribute significantly to the oxidation of ammonia to nitrite in nature (Aakra et al., 2000; Jiang \& Bakken, 1999; Kowalchuk et al., 1997; McCaig et al., 1994; Stephen et al., 1996). However, the limited number of $16 \mathrm{~S}$ rDNA sequences from pure cultures available biases these results, and the specificity of the oligonucleotides used as PCR primers or hybridization probes has been questioned (Aakra et al., 2000; Utåker \& Nes, 1998).

The similarity values between 16S rDNA sequences from some AOB are so high that the few nucleotides distinguishing them may be ascribed to sequencing ambiguities rather than true sequence differences (Utåker et al., 1995). Hence, alternative techniques to $16 \mathrm{~S}$ rRNA gene sequencing are needed to clarify the phylogeny of many $\beta$-proteobacterial AOB. Analysis of the $16 \mathrm{~S}-23 \mathrm{~S}$ rDNA intergenic spacer region (ISR) is one such technique, which can be applied as a supplement to $16 \mathrm{~S}$ rRNA gene sequencing. ISRs evolve much faster than $16 \mathrm{~S}$ rRNA genes, probably because of less functional restriction, and can, thus, be used to trace more recent evolutionary events (species and strain level) (Barry et al., 1991; Garcia-Martinez et al., 1999; Gürtler \& Stanisich, 1996). Several studies have demonstrated the relevance of ISR sequence analysis for phylogenetic purposes, most of which have been performed with pure cultures of microorganisms (Barry et al., 1991; Garcia-Martinez et al., 1999; Gürtler \& Stanisich, 1996; Jensen et al., 1993). Compared to 16S rRNA gene analysis, the use of ISR analysis has technical advantages: ISRs are usually shorter than the 16S rRNA gene, which makes sequencing less laborious. In some organisms differently sized ISRs may be easily separated, by standard agarose gel electrophoresis; cloning might not be necessary. More ISR sequences are needed, however, to increase the practical value of environmental studies based on ISR analysis. At present, the number of ISR sequences available in the international sequence databases is relatively low, which limits the use of ISR sequences in studies of microbial diversity. Moreover, the sequence variation between ISRs from different rrn operons within a bacterium may be as large as the sequence variation between ISRs from different organisms (Jensen et al., 1993; Nagpal et al., 1998). Consequently, ISR analysis of natural populations of bacteria with a single or few rrn operons per cell will be more applicable. The potential of exploiting the ISR in studies of natural samples has been shown (Acinas et al., 1999; Borneman \& Triplett, 1997; Robleto et al., 1998). The results from these studies show that ISR analysis is a promising tool for characterization of natural microbial populations. In a previous study of 12 AOB isolates, it was shown that these organisms have only one rrn operon per genome and analysis of ISR should therefore be a suitable and useful tool for studies of AOB (Aakra et al., 1999a).

Species determination of more cultured AOB (Nitro- sospira spp. in particular) is needed to determine whether there is good correlation between phylogeny based on rDNA and species affiliations. If DNA sequence information from environmental samples can be used to infer the species identity of the organisms found in the actual environment, the interpretation can be simplified and give an improved resolution of the complexity of natural microbial populations. The basis for species determination of bacteria is DNA-DNA hybridization data. The DNA of strains within one bacterial species should reveal 50-70\% DNA-DNA reassociation and phenotypic criteria should agree with the DNA homology values. In fact, phenotypic data for strains are decisive of whether a species should be delineated at 60 or $80 \%$ similarity level (Stackebrandt \& Goebel, 1994). 16S rDNA sequence data cannot be used to determine species identity, but $16 \mathrm{~S}$ rDNA sequence similarity values below $97 \%$ indicate that the organisms belong to different species (Stackebrandt \& Goebel, 1994).

In this paper, the evolution of $38 \mathrm{AOB}$ isolates has been studied by comparison of 16S rRNA gene-based phylogeny with ISR sequence-based phylogeny and species identities based on DNA homology values. On the basis of this information, the suitability and relevance of $16 \mathrm{~S}$ rDNA and ISR for studies of AOB diversity has been evaluated.

\section{METHODS}

Bacteria and growth conditions. The AOB were grown in the dark at room temperature $\left(22-24{ }^{\circ} \mathrm{C}\right)$. The origin and abbreviations for the isolates studied are given in Table 1. Terrestrial isolates (Nitrosospira and some Nitrosomonas isolates, see Table 1) were grown in a liquid ammonium medium as described by Jiang \& Bakken (1999). Isolates from brackish water and marine habitats (Nitrosococcus and some Nitrosomonas isolates) were grown in the media described by Koops et al. (1991).

Cell lysis and preparation of PCR-ready DNA. Preparation of PCR-ready DNA was performed using Dynabeads DNA Direct system I (Dynal) as recommended by the manufacturer.

Amplification of 16S rDNA and the 16S-23S rDNA ISR. PCRs ( 50 or $100 \mu \mathrm{l}$ ) were run with $\operatorname{Taq}$ polymerase $(1.25$ or $2.5 \mathrm{U}$ ) (Advanced Biotechnologies), $10 \mathrm{mM}$ Tris $/ \mathrm{HCl}(\mathrm{pH} 8 \cdot 3$ ), $50 \mathrm{mM} \mathrm{KCl}, 1.5 \mathrm{mM} \mathrm{MgCl}_{2}, 1$ or $2 \%$ (v/v) formamide, $200 \mu \mathrm{M}$ dNTP, $1 \mu \mathrm{M}$ each primer (Gibco-BRL) and $1-2 \mu 1$ (25-50 ng) genomic DNA, prepared as described above. All PCRs were run in a PTC-100 (Programmable Thermal Controller; MJ Research). All primers used are listed in Table 2. 16S rDNA was amplified using the primers $1 \mathrm{~F}$ and 5R (Table 2) during 35 cycles of $94{ }^{\circ} \mathrm{C}$ for $1 \mathrm{~min}, 56^{\circ} \mathrm{C}$ for $1 \mathrm{~min}$ and $72^{\circ} \mathrm{C}$ for $1 \mathrm{~min} 30 \mathrm{~s}$. The ISR was amplified using the primers $7 \mathrm{~F}$ and $13 \mathrm{R}$ (Table 2) during 35 cycles of $94^{\circ} \mathrm{C}$ for $1 \mathrm{~min}, 52^{\circ} \mathrm{C}$ for $1 \mathrm{~min}$ and $72^{\circ} \mathrm{C}$ for $1 \mathrm{~min}$. All PCRs were preceded by a 3 min hot start at $97^{\circ} \mathrm{C}$ and ended by a $10 \mathrm{~min}$ incubation at $72^{\circ} \mathrm{C}$. Prior to sequencing, PCR products were purified using silica gel columns (QIAquick PCR Purification Kit; Qiagen).

DNA sequencing. Cycle sequencing was performed using the ABI Prism BigDye Terminator Cycle Sequencing Ready Reaction Kit and an ABI Prism 377 DNA sequencer, as 
Table 1. Abbreviations and origin of the organisms studied

\begin{tabular}{|c|c|c|}
\hline Isolate (abbreviation) & Origin/strain no. & Reference \\
\hline Nitrosomonas communis $\mathrm{Nm} 2^{\mathrm{T}}(\mathrm{Nm} 2)$ & Soil, Corfu & Koops et al. (1991) \\
\hline Nitrosomonas ureae $\mathrm{Nm} 10^{\mathrm{T}}(\mathrm{Nm} 10)$ & Soil, Sardinia & Koops et al. (1991) \\
\hline Nitrosomonas marina $\mathrm{Nm} 22^{\mathrm{T}}(\mathrm{Nm} 22)$ & Sea water, South Pacific & Koops et al. (1991) \\
\hline Nitrosomonas sp. Nm33 (Nm33) & Soil, Japan & Koops et al. (1991) \\
\hline Nitrosomonas aestuarii $\mathrm{Nm} 36^{\mathrm{T}}(\mathrm{Nm} 36)$ & Sea water, North Sea & Koops et al. (1991) \\
\hline Nitrosomonas sp. Nm41 (Nm41) & Soil, St Petersburg & Koops et al. (1991) \\
\hline Nitrosomonas oligotropha $\mathrm{Nm} 45$ ( $\mathrm{Nm} 45)$ & Soil, Hamburg & Koops et al. (1991) \\
\hline Nitrosomonas europaea $\mathrm{Nm} 50^{\mathrm{T}}(\mathrm{Nm} 50)$ & Soil, USA & Type strain NCIMB $11850^{\mathrm{T}}$ \\
\hline Nitrosomonas sp. Nm51 (Nm51) & Sea water, Gulf of Maine & Koops et al. (1991) \\
\hline Nitrosomonas cryotolerans $\mathrm{Nm} 55^{\mathrm{T}}(\mathrm{Nm} 55)$ & Sea water, Alaska/ATCC 49181 & Jones et al. (1988) \\
\hline Nitrosomonas eutropha $\mathrm{Nm} 57^{\mathrm{T}}(\mathrm{Nm} 57)$ & Municipal sewage, Chicago & Koops \& Harms (1985) \\
\hline Nitrosomonas sp. F5 (F5) & Animal house, Norway & Aakra et al. (1999a, b) \\
\hline Nitrosomonas sp. F6 (F6) & Animal house, Norway & Aakra et al. $(1999 \mathrm{a}, \mathrm{b})$ \\
\hline Nitrosospira multiformis $\mathrm{N}^{113^{\mathrm{T}}}$ (N113) & Soil, Surinam/NCIMB 11849 & Koops \& Harms (1985) \\
\hline Nitrosospira sp. N120 (N120) & Soil, Italy & H.-P. Koops (unpublished) \\
\hline Nitrosospira sp. 24C (24C) & Agricultural soil, Minnesota & E. Schmidt (unpublished) \\
\hline Nitrosospira sp. Nsp1 (Nsp1) & Soil, Sardinia & Koops \& Harms (1985) \\
\hline Nitrosospira sp. Nsp2 (Nsp2) & Soil, Hamburg & Koops \& Harms (1985) \\
\hline Nitrosospira briensis Nsp10 $0^{\mathrm{T}}$ (Nsp10) & Soil, Crete/ATCC 25071 & Koops \& Harms (1985) \\
\hline Nitrosospira sp. Nsp12 (Nsp12) & Soil, Hamburg & Koops \& Harms (1985) \\
\hline Nitrosospira sp. Nsp17 (Nsp17) & Soil, Iceland & Koops \& Harms (1985) \\
\hline Nitrosospira sp. 39-19 (39-19) & Agricultural soil, Minnesota & E. Schmidt (unpublished) \\
\hline Nitrosospira sp. 40KI (40KI) & Loam, garden soil, Norway & Utåker et al. (1995) \\
\hline Nitrosospira sp. A16 (A16) & Agricultural soil, Norway & Aakra et al. $(1999 \mathrm{a}, \mathrm{b})$ \\
\hline Nitrosospira sp. A4 (A4) & Agricultural soil, Norway & Aakra et al. (1999a, b) \\
\hline Nitrosospira sp. AF (AF) & Sandy loam, Zambia & Utåker et al. (1995) \\
\hline Nitrosospira sp. B6 (B6) & Sewage treatment column, Norway & Utåker et al. (1995) \\
\hline Nitrosospira sp. F3 (F3) & Animal house, Norway & Aakra et al. (1999a, b) \\
\hline Nitrosospira sp. III2 (III2) & Spruce forest, Norway & Utåker \& Nes (1998) \\
\hline Nitrosospira sp. III7 (III7) & Spruce forest, Norway & Utåker \& Nes (1998) \\
\hline Nitrosospira sp. Ka3 (Ka3) & Lead-contaminated soil, Norway & Aakra et al. (1999a, b) \\
\hline Nitrosospira sp. Ka4 (Ka4) & Lead-contaminated soil, Norway & Aakra et al. (1999a, b) \\
\hline Nitrosospira sp. L115 (L115) & Peat bog, Finland & Utåker et al. (1995) \\
\hline Nitrosospira sp. O13 (O13) & Agricultural soil, Norway & Aakra et al. (1999a, b) \\
\hline Nitrosospira sp. O4 (O4) & Agricultural soil, Norway & Aakra et al. (1999a, b) \\
\hline Nitrosospira tenuis $\mathrm{Nv}^{\mathrm{T}}(\mathrm{Nv} 1)$ & Soil, Hawaii & Koops \& Harms (1985) \\
\hline Nitrosospira sp. Nv6 (Nv6) & Soil, Goroko/Danlo Pas & Koops \& Harms (1985) \\
\hline 'Nitrosococcus mobilis' $\mathrm{Nc}^{\mathrm{T}}(\mathrm{Nc} 2)$ & Sea water, North Sea & Koops \& Harms (1985) \\
\hline
\end{tabular}

recommended by the supplier (Applied Biosystems). To sequence the $16 \mathrm{~S}$ rRNA gene, the primers $1 \mathrm{~F}, 11 \mathrm{~F}, 15 \mathrm{~F}, 16 \mathrm{~F}$, 9R, 3R, 4R and 5R (Table 2) were used, giving overlapping sequences, on both strands. For ISR sequencing the primers 7F, 5F, ISR-F, ISR-R and 13R (Table 2), also covering both strands, were applied.

Data analysis. The sequences obtained were analysed and edited using programs in the Genetics Computer Group (GCG) program package, version 8.1 (Program Manual for the Wisconsin Package, Version 8, September 1994, Genetics Computer Group, Madison, WI, USA). Alignments of sequences were performed in CLUSTAL W (http://www2.ebi.ac.uk/clustalw/) (Thompson et al., 1994). Prior to construction of phylogenetic trees the alignments were carefully corrected manually and the $16 \mathrm{~S}$ rRNA gene sequences were adjusted to equal lengths (approx. $1205 \mathrm{bp}$ ). The ISR sequences were stripped from the $3^{\prime}$ end of the $16 \mathrm{~S}$ rRNA gene and the $5^{\prime}$ end of the $23 \mathrm{~S}$
rRNA gene. Phylogenetic analysis was performed by using different methods: distance matrix (neighbour-joining), maximum-parsimony and maximum-likelihood. The programs used for the phylogenetic analysis were DNADIST, NEIGHBOUR, DNAPARS, SEQBOOT, CONSENSE and DNAML in the PHYLIP program package, version 3.5 (Felsenstein, 1993). Bootstrap analyses of neighbour-joining and maximumparsimony trees were performed with 100 replicates. Similarity values for the sequences were estimated using the program HOMOLOGIES in the EGCG program package (Program Manual for the EGCG Package, Version 8.1.0, March 1996, Hinxton Hall, Cambridge). The GCG, EGCG and PHYLIP programs were all run on a UNIX mainframe computer. Phylogenetic trees were visualized using TREEVIEW software, version 1.5 (Page, 1996) (http://taxonomy. zoology.gla.ac.uk/rod/treeview.html).

DNA sequence accession numbers. The accession numbers are indicated in Fig. 1. Nearly full-length 16S rDNA 
sequences of $\mathrm{Nm} 2, \mathrm{Nm} 10, \mathrm{Nm} 55, \mathrm{Nm} 57$ and $\mathrm{Nc} 2$ have been published previously (Head et al., 1993; PommereningRöser et al., 1996), but to resolve some of the ambiguities of these sequences, they have been sequenced again here. The following sequences were extracted from the nucleotide sequence databases: Nitrosospira sp. AF (16S rDNA and ISR), Nitrosospira sp. B6 (16S rDNA and ISR), Nitrosospira sp. 40KI (16S rDNA and ISR), Nitrosospira sp. L115 (16S rDNA and ISR), Nitrosospira sp. III2 (16S rDNA and ISR), Nitrosospira sp. III7 (16S rDNA and ISR), Nitrosomonas europaea Nm50 (16S rDNA and ISR), Nitrosospira multiformis N113 (16S rDNA and ISR), Nitrosospira sp. F3 (16S rDNA and ISR), Nitrosomonas sp. F5 (16S rDNA and ISR), Nitrosospira sp. A4 (16S rDNA and ISR), Nitrosospira sp. A16 (16S rDNA and ISR), Nitrosospira sp. Ka3 (16S rDNA), Nitrosospira sp. Ka4 (16S rDNA), Nitrosospira sp. O4 (16S rDNA), Nitrosospira sp. O13 (16S rDNA), Nitrosomonas sp. F6 (16S rDNA), Nitrosomonas marina $\mathrm{Nm} 22$ (16S rDNA).

DNA-DNA homology determination. DNA-DNA hybridizations were performed as described previously (Koops \& Harms, 1985).

\section{RESULTS AND DISCUSSION}

Nearly full-length 16S rDNA sequences were obtained for the Nitrosospira isolates 24C, 39-19, N120, Nsp1, Nsp2, Nsp10, Nsp12, Nsp17, Nv1 and Nv6, for the Nitrosomonas isolates $\mathrm{Nm} 2, \mathrm{Nm} 10, \mathrm{Nm} 33, \mathrm{Nm} 36$, Nm41, Nm45, Nm51, Nm55 and Nm57, and for 'Nitrosococcus mobilis' Nc2 (Figs 1 and 2, Table 1). These new $16 \mathrm{~S}$ rDNA sequences were aligned to previously published $16 \mathrm{~S}$ rDNA sequences of $\mathrm{AOB}$ and all sequences were adjusted to equal length (approx. $1205 \mathrm{bp)}$ before phylogenetic analysis. Furthermore, the ISR of the Nitrosospira isolates 24C, 39-19, N120, Nsp1, Nsp2, Nsp10, Nsp12, Nsp17, $\mathrm{Nv} 1, \mathrm{Nv6}, \mathrm{Ka} 3, \mathrm{Ka} 4, \mathrm{O} 4$ and O13, the Nitrosomonas isolates $\mathrm{F} 6, \mathrm{Nm} 2, \mathrm{Nm} 22, \mathrm{Nm} 10, \mathrm{Nm} 33$, Nm36, Nm41, Nm45, Nm51, Nm55 and Nm57, and 'Nitrosococcus mobilis' Nc2 were sequenced and analysed. For phylogenetic analysis of the 16S rRNA gene and ISR sequences neighbour-joining, maximumparsimony and maximum-likelihood analyses were performed. However, neighbour-joining appeared to be the most suitable method for phylogenetic analysis and comparison of these two datasets. Maximumparsimony is probably a suitable method for phylogenetic analysis of the highly similar 16S rDNA sequences from $\mathrm{AOB}$. For analysis of the more variable ISR sequences, however, parsimony analysis appears more problematic. Most likely, the rapid evolution of the ISR sequences may have led to saturation of several nucleotide sites. In a parsimony analysis such saturated sites may be misleading; they will be overprinted and lost. Nevertheless, both datasets were analysed by neighbour-joining and maximumparsimony, with bootstrapping, to test the precision of the branching patterns, and by the maximumlikelihood method. The branching patterns of the trees obtained by the different methods were the same and only the neighbour-joining distance trees are shown here (Figs 1 and 2). The topology of the trees in Fig. 1 and their corresponding majority rule consensus trees of the bootstrap analyses (Fig. 2) were nearly identical. In the phylogenetic trees shown (Figs 1 and 2) the organisms have been divided into groups (named $\mathrm{NmA}-\mathrm{C}$ for Nitrosomonas spp. and NspA-D for Nitrosospira spp.) based upon their clustering patterns in the trees. Some of the groups contain representatives of more than one species, as defined by DNA homology values. However, isolates belonging to one species do all cluster within the same phylogenetic group, in which representatives of another species may accompany them or not.

\section{Phylogeny of AOB}

16S rDNA-based phylogeny: Nitrosomonas. Within the Nitrosomonas genus, the resolution of the phylogeny based on $16 \mathrm{~S}$ rDNA sequences is relatively good, considering the overall high similarity values of these sequences among AOB. Most of the nodes are supported with high bootstrap values ( $>50 \%$; Fig. 2). The terrestrial Nitrosomonas isolates (F5, F6, Nm50, $\mathrm{Nm} 57, \mathrm{Nm} 2, \mathrm{Nm} 33$ and Nm41) can be distinguished from marine Nitrosomonas isolates ( $\mathrm{Nm} 22, \mathrm{Nm} 36$, $\mathrm{Nm} 51$ and Nm55), although the node separating $\mathrm{Nm} 2$, $\mathrm{Nm} 33$ and $\mathrm{Nm} 41$ from $\mathrm{Nm} 10, \mathrm{Nm} 22, \mathrm{Nm} 36, \mathrm{Nm} 45$ and $\mathrm{Nm} 51$ (cluster $\mathrm{NmB}$ ) is supported by only $48 \%$ of the bootstrap replicates. The Nm55 isolate is separated from the other Nitrosomonas isolates, being the Nitrosomonas isolate most closely related to the Nitrosospira group (bootstrap value $85 \%$ ), based on $16 \mathrm{~S}$ rDNA sequences. The $16 \mathrm{~S}$ rDNA sequence similarities in the Nitrosomonas cluster vary from $90.9 \%$ (between F5 and Nm10) to $99 \cdot 5 \%$ (between F6 and Nm57). The similarity values of the 16S rDNA sequences of Nm36, $\mathrm{Nm} 22$ and $\mathrm{Nm} 51$ (in cluster $\mathrm{NmB}$ ) are higher than $97 \cdot 0 \%$, indicating that these organisms may be strains of the same species (Stackebrandt \& Goebel, 1994). However, DNA homology values show that they all belong to different species (Koops et al., 1991). Likewise, the 16S rDNA similarity value for Nm50 and $\mathrm{Nm} 57$ (cluster NmA) is $97 \cdot 5 \%$. For Nm41, Nm33 and $\mathrm{Nm} 2$ (cluster $\mathrm{NmB}$ ) the similarity values vary between $97 \cdot 1$ and $98.3 \%$, but the DNA homology values are so low that they can be assigned to three different species (Koops et al., 1991; Koops \& Harms, 1985). These data demonstrate that within the Nitrosomonas genus, nearly identical $16 \mathrm{~S}$ rDNA sequences do not guarantee species identity, a phenomenon that has been described also for other organisms (Fox et al., 1992). The DNA homologies between F5, F6, Nm50 and Nm57 have not been determined, since we were not able to obtain sufficient amounts of cell material of F5 and F6 to perform the DNA-DNA hybridization experiments. Hence, their species affiliations are still unknown.

165 rDNA-based phylogeny: Nitrosospira. Among the Nitrosospira isolates, the result of the phylogenetic analysis of the $16 \mathrm{~S}$ rDNA sequences is more complex. 
Table 2. Oligonucleotides used for amplification and sequencing of $16 S$ rDNA and ISR

\begin{tabular}{|c|c|c|c|c|}
\hline Primer & Sequence $\left(5^{\prime}-3^{\prime}\right)$ & Target & Position in target & Reference \\
\hline $1 \mathrm{~F}$ & gagtttgatcctggetcag & $16 \mathrm{~S}$ rDNA & $9-27^{*}$ & Weisburg et al. (1991) \\
\hline $11 \mathrm{~F}$ & tggcgaaggcggccccetgga & $16 \mathrm{~S}$ rDNA & $50-70 *$ & Edwards et al. (1989) \\
\hline $15 \mathrm{~F}$ & acgggaggcagcagt & $16 \mathrm{~S}$ rDNA & $343-357^{*}$ & Stackebrandt \& Charfreitag (1990) \\
\hline $16 \mathrm{~F}$ & aactcaaatgaattgacggg & $16 \mathrm{~S}$ rDNA & $907-926^{*}$ & Lane et al. (1985) \\
\hline $7 \mathrm{~F}$ & gccttgtacacaccgc & $16 \mathrm{~S}$ rDNA & $1386-1401 *$ & Modified from Lane et al. (1985) \\
\hline $5 \mathrm{~F}$ & aagtcgtaacaaggtaacc & $16 \mathrm{~S}$ rDNA & $1492-1510^{*}$ & Stackebrandt \& Charfreitag (1990) \\
\hline ISR-F & tgataagcgtggggtcgg & ISR & & Aakra et al. (1999a) \\
\hline $9 \mathrm{R}$ & cgtattaccgcggetgct & $16 \mathrm{~S}$ rDNA & $519-536^{*}$ & Lane et al. (1985) \\
\hline $3 \mathrm{R}$ & cccgtcaattcatttgagtt & $16 \mathrm{~S}$ rDNA & $907-926^{*}$ & Reverse of $16 \mathrm{~F}$; Lane et al. (1985) \\
\hline $4 \mathrm{R}$ & gacgggcggtgtgta & $16 \mathrm{~S}$ rDNA & $1392-1406^{*}$ & Lane et al. (1985) \\
\hline $5 \mathrm{R}$ & ggttaccttgttacgactt & $16 \mathrm{~S}$ rDNA & $1492-1510^{*}$ & Stackebrandt \& Charfreitag (1990) \\
\hline ISR-R & gatkaccectgcttgca & ISR & & Aakra et al. (1999a) \\
\hline $13 \mathrm{R}$ & gccaaggcatccaccacatg & $23 \mathrm{~S}$ rDNA & $18-37 \dagger$ & Aakra et al. (1999a) \\
\hline
\end{tabular}

* E. coli numbering according to Brosius et al. (1978).

$\dagger$ E. coli numbering according to Brosius et al. (1980).

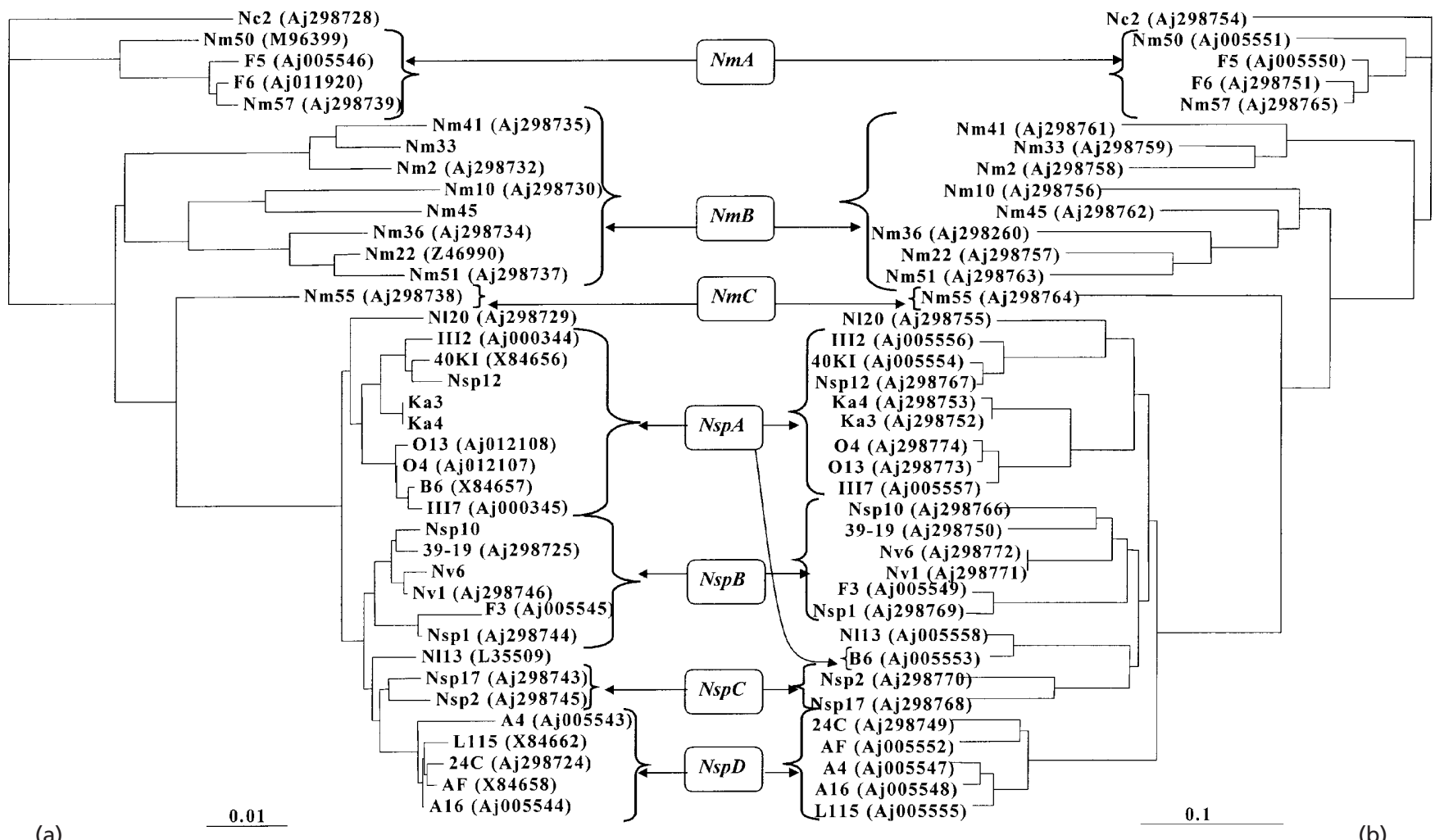

(a)

Fig. 1. Neighbour-joining distance trees based on $16 \mathrm{~S}$ rRNA gene sequences (a) and 16S-23S rDNA ISR sequences (b) from AOB in the $\beta$-subclass of the Proteobacteria. The relative distances were calculated using the DNADIST program in the PHYLIP program package (Felsenstein, 1993). Abbreviations of the organisms are given in Table 1. 'Nitrosococcus mobilis' $\mathrm{Nc2}$ was defined as an outgroup organism in both trees. The various groups of organisms have been named NmA-NmC for the Nitrosomonas group and NspA-NspD for the Nitrosospira group. Accession numbers for the sequences are given in parentheses. 
$16 \mathrm{~S}$ rDNA

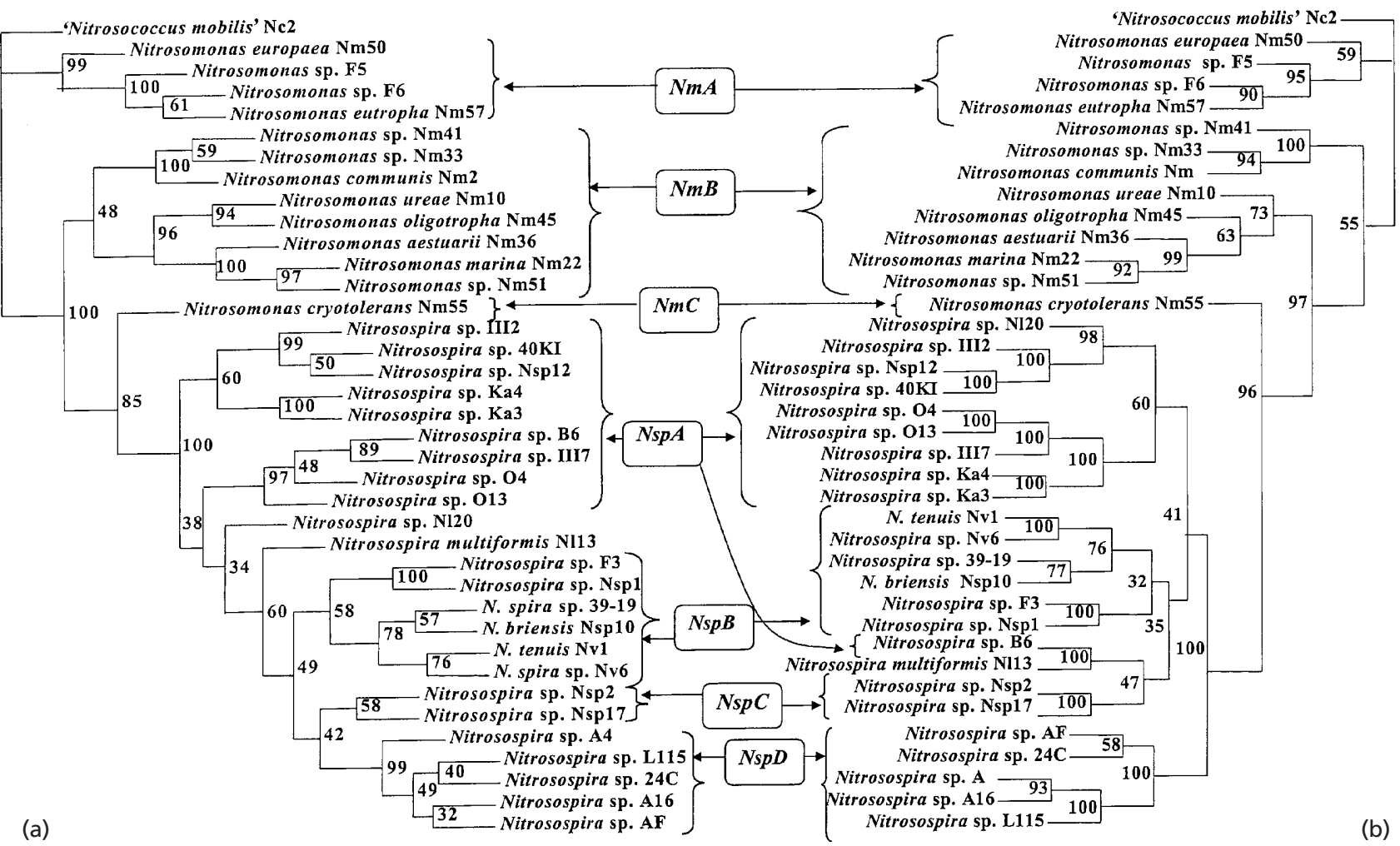

16S-23S rDNA Intergenic Spacer Region (ISR)

(b)

Fig. 2. Majority rule consensus trees of bootstrapped neighbour-joining analyses of $16 S$ rDNA and ISR sequences from AOB, corresponding to the neighbour-joining distance trees in Fig. 1. 'Nitrosococcus mobilis' Nc2 was defined as an outgroup organism. The clusters are denoted as in Fig. 1. The consensus tree based on the 16S rDNA sequence data are shown on the left (a); the ISR-based tree is shown on the right (b). For the Nitrosomonas isolates, the topologies of and differences between the trees are the same as in the trees shown in Fig. 1. Within the Nitrosospira clade, however, it is less clear. The ISR-based consensus tree displays the same topology as the neighbour-joining distance tree (Fig. 1b), but the consensus tree based on 16S rDNA sequences (a) differs slightly from the corresponding tree in Fig. 1(a). In the 16S rDNA consensus tree (a) the NspA organisms are separated from each other into three clusters, but only one of the branch points leading to this separation is fully supported by the bootstrap analysis.

The 24 Nitrosospira isolates included in Fig. 1(a) were divided into four clusters, some of them supported by low bootstrap values (Fig. 2a). The similarity values between the Nitrosospira 16S rRNA genes are high, from $96.3 \%$ (between A4 and III2) to $100 \%$ (between Ka3 and Ka4). Teske et al. (1994) argued that 'Nitrosolobus', due to its distinct morphological characteristics, should not be included in the Nitrosospira genus, but in that report only one 'Nitrosolobus' 16S rDNA sequence was analysed (N113). In the present study, one new isolate with 'Nitrosolobus' morphology (N120) has been analysed by rDNA sequencing. Both the N113 and N120 group within the Nitrosospira clade, but they appear as marginal groups in the 16S rDNA, as well as in the ISR-based tree (discussed below). In the neighbour-joining tree (Fig. 1a) N120 appears to be most closely related to the organisms of cluster NspA. However, the position of N120 appears unclear, since it is separated from the other NspA organisms in the majority rule consensus tree (Fig. 2a). In the latter tree, cluster NspA is split into three groups, although two of the branch points are not statistically significant (bootstrap values 38 and $34 \%$ ). The N113 isolate appears most closely related to the NspC organisms (Nsp2 and Nsp17). In the ISR-based tree, the peculiarity of $\mathrm{N} 113$ is less obvious than in the $16 \mathrm{~S}$ rDNA-based tree, since B6 groups together with N113 here. However, we do not believe this reflects a true phylogenetic relationship, since the phylogenetic position of B6 probably is within the NspA cluster, as seen both in the $16 \mathrm{~S}$ rDNA-based tree and in trees based on partial sequences of the ammonia monooxygenase gene $(\AA$. Aakra, unpublished results). It is tempting to speculate that the lobate morphology is a trait that, in terms of evolutionary rates, has evolved recently and we recommend that 'Nitrosolobus' should be kept as a genus alongside Nitrosospira until more AOB with lobate cell morphology have been examined.

Species affiliations of Nitrosospira spp. based on DNA-DNA homology values. Previously, DNA-DNA homology values have been obtained for nine of the Nitrosospira isolates included in this study: N120 (H.-P. Koops, 
unpublished results), N113, Nsp1, Nsp2, Nsp10, Nsp12, Nsp17, Nv1 and Nv6 (Koops \& Harms, 1985). According to these data, they all belong to different species, despite the high $16 \mathrm{~S}$ rDNA similarity values that vary between 97.6 and $99.7 \%$. This demonstrates again that $16 \mathrm{~S}$ rDNA similarity cannot be used to infer species identity. In this work DNA-DNA hybridization experiments have been performed with $\mathrm{AF}$, L115, A4, A16, 24C, 40KI, III2, 39-19, F3, B6 and III7. According to the results of these experiments, 24C, AF, L115, A16 and A4, i.e. the organisms constituting the NspD cluster, belong to the same species (DNA homology values $52-81 \%$ ), a species that has not been described before. According to the definition of AOB clusters by Stephen et al. (1996), the NspD organisms belong to 'Nitrosospira cluster 3'. Likewise, B6 and III7 (DNA homology value 74\%) represent a hitherto undescribed Nitrosospira species within 'Nitrosospira cluster 2' (cluster definitions by Stephen et al., 1996). 40KI, III2 and Nsp12 constitute a subgroup within NspA and they belong to the same species (homology values between 68 and $73 \%$ ). Within the NspB cluster, F3 and Nsp1 appear to belong to one species (homology value 69\%) and 39-19 belongs to the same species as Nsp10 (homology value $55 \%$ ). DNA-DNA hybridization experiments have not been performed with the other Nitrosospira isolates, since we have not been able to obtain sufficient cell material from these organisms.

Phylogeny of $A O B$ based on ISR sequences. Based on 12 sequences of the $16 \mathrm{~S}-23 \mathrm{~S}$ rDNA ISR it has been suggested that phylogenetic analysis of the ISR could be used as a supplementary tool to 16S rDNA sequencing when studying the diversity of AOB (Aakra et al., 1999a). In the present work, the ISRs from 26 more AOB isolates have been amplified, sequenced, aligned and analysed phylogenetically, resulting in the tree shown in Fig. 1(b). The size of the ISR varied from 394 bp in Nm57 and F6, to 708 bp in 24C. Generally, the ISRs from the Nitrosomonas and Nitrosococcus isolates are shorter (394-618 bp) than the ISRs from the Nitrosospira isolates (633-708 bp) (Table 3), but the differences are not sufficient enough to be used for genus recognition, as discussed previously (Aakra et al., 1999a).

Compared to the 16S rRNA gene sequences, the similarity values of the ISR sequences are low. Within the Nitrosomonas and Nitrosococcus genera, the similarity values vary from 43.0 to $97.0 \%$. For the Nitrosospira isolates, the similarity values vary from $65.4 \%$ to almost identity $(99 \cdot 4 \%)$. This is not merely due to ISR size differences, because those organisms, having equal sized ISRs, have ISR similarity values of 97.0 (F6 and Nm57), 77.6 (Nm33 and Nm41), 97.8 (40KI and Nsp12) and 86.2\% (O4 and Ka3). To a certain extent, the similarity of the ISRs can be ascribed to conserved regions of the ISR, because all the AOB isolates examined contain two tRNA genes (tRNA-Ile and tRNA-Ala) near the 5' end of the ISR. The conserved regions of the ISR are nearly identical
Table 3. Length of the new $16 \mathrm{~S}-23 \mathrm{~S}$ rDNA ISRs (bp)

ISRs of remaining isolates have been presented elsewhere (Aakra et al., 1999a). The clusters are denoted as in Figs 1 and 2.

\begin{tabular}{|c|c|c|}
\hline Isolate & ISR (bp) & Cluster \\
\hline Nitrosomonas sp. F6 & 394 & $\mathrm{NmA}$ \\
\hline Nitrosomonas eutropha $\mathrm{Nm} 57$ & 394 & $\mathrm{NmA}$ \\
\hline 'Nitrosococcus mobilis' $\mathrm{Nc} 2$ & 423 & $\begin{array}{c}\text { Outgroup } \\
\text { organism }\end{array}$ \\
\hline Nitrosomonas oligotropha $\mathrm{Nm} 45$ & 497 & $\mathrm{NmB}$ \\
\hline Nitrosomonas ureae $\mathrm{Nm} 10$ & 518 & $\mathrm{NmB}$ \\
\hline Nitrosomonas communis $\mathrm{Nm} 2$ & 531 & $\mathrm{NmB}$ \\
\hline Nitrosomonas sp. Nm33 & 548 & $\mathrm{NmB}$ \\
\hline Nitrosomonas sp. Nm41 & 548 & $\mathrm{NmB}$ \\
\hline Nitrosomonas marina $\mathrm{Nm} 22$ & 566 & $\mathrm{NmB}$ \\
\hline Nitrosomonas aestuarii $\mathrm{Nm} 36$ & 596 & $\mathrm{NmB}$ \\
\hline Nitrosomonas cryotolerans $\mathrm{Nm} 55$ & 612 & $\mathrm{NmC}$ \\
\hline Nitrosomonas sp. Nm51 & 618 & $\mathrm{NmB}$ \\
\hline Nitrosospira tenuis $\mathrm{Nv}^{\mathrm{T}}$ & 633 & NspB \\
\hline Nitrosospira sp. Nv6 & 637 & NspB \\
\hline Nitrosospira sp. 39-19 & 643 & NspB \\
\hline Nitrosospira sp. Nsp2 & 649 & NspC \\
\hline Nitrosospira sp. Nsp17 & 654 & NspC \\
\hline Nitrosospira briensis Nsp10 & 661 & NspB \\
\hline Nitrosospira sp. N120 & 664 & NspA \\
\hline Nitrosospira sp. Nsp12 & 674 & NspA \\
\hline Nitrosospira sp. Nsp1 & 675 & NspB \\
\hline Nitrosospira sp. $\mathrm{O} 13$ & 676 & NspA \\
\hline Nitrosospira sp. Ka3 & 677 & NspA \\
\hline Nitrosospira sp. $\mathrm{O} 4$ & 677 & NspA \\
\hline Nitrosospira sp. Ka4 & 678 & NspA \\
\hline Nitrosospira sp. $24 \mathrm{C}$ & 708 & NspD \\
\hline
\end{tabular}

in all the AOB isolates tested and constitute approximately $200 \mathrm{bp}$. The heterogeneity of the ISRs of the $\mathrm{AOB}$ is largely due to insertions and deletions outside the conserved regions. These differences often include nucleotide blocks, rather than single bp substitutions, which might be useful for possible future construction of specific oligonucleotides to be used for studies of AOB communities.

\section{The phylogeny of AOB based on ISR sequences complements the $16 \mathrm{~S}$ rDNA-based phylogeny}

When comparing phylogenetic trees constructed on the basis of different genes, small topology differences must be expected, since it is not likely that functionally independent markers have preserved information from the same periods of evolution. When comparing the two neighbour-joining trees in Fig. 1, the phylogeny of the 16S rRNA gene sequences and the 16S-23S rDNA ISR, appear consistent. The main difference between the two trees is that the ISR-based tree has a much higher resolution, indicated by the bars reflecting the relative distances (Fig. 1). After the submission of this paper, a comparison of the phylogeny of various AOB, 
based on 16S rRNA gene sequences and amo $A$ sequences was published (Purkhold et al., 2000). This study, which focuses on Nitrosomonas spp. concluded that the evolution of the ammonia monooxygenase gene is similar, though not identical, to that of the $16 \mathrm{~S}$ rRNA gene. Although the organisms constituting the $\mathrm{NmB}$ group in the present paper have been divided into three groups by Purkhold et al. (2000), their results are in agreement with the results presented in this paper.

With a few exceptions, the clustering of the Nitrosomonas isolates in the ISR tree (Fig. 1a) is the same as in the 16S rDNA tree (Fig. 1b). The Nitrosomonas isolates have been divided into three subclusters denoted $\mathrm{NmA}-\mathrm{C}$ (Figs 1 and 2), and within NmA and $\mathrm{NmB}$ some differences can be seen between the $16 \mathrm{~S}$ rDNA- and the ISR-based trees. Possibly, the differences can be explained by the fast evolution of the ISR compared to the 16S rRNA gene. In the Nitrosomonas cluster, differences between the two trees regarding branching patterns are found in $\mathrm{NmB}$, where $\mathrm{Nm} 10$ and Nm45 cluster together in the 16S rDNAbased tree (Fig. 1a), whereas they are separated, but still within $\mathrm{NmB}$, in the ISR-based tree (Fig. 1b). In the 16S rDNA-based tree, $\mathrm{Nm} 2$ forms its own clade, whereas in the ISR-based tree it clusters with Nm33. Conversely, Nm41 is alone in the ISR tree, but clusters with Nm33 in the 16S tree. The nodes dividing these organisms are all supported by relatively high bootstrap values in the consensus trees (Fig. 2) (59-100\%). According to the ISR tree, the separation of the $\mathrm{NmB}$ organisms from $\mathrm{Nm} 55$ (in $\mathrm{NmC}$ ) appears to have occurred in two steps, while the 16S rDNA tree suggests one step. In the ISR tree $\mathrm{Nm} 41, \mathrm{Nm} 2$ and Nm33 have, apparently, branched off from the other $\mathrm{NmB}$ organisms at an earlier stage in the evolution than is revealed by the $16 \mathrm{~S}$ rDNA tree (Fig. 1a). This phenomenon may reflect the fact that the ISR reveal more details of the evolution than the functional ribosomal genes do.

The Nitrosospira isolates have been divided into four subclusters, denoted NspA-D (Fig. 1b). Among these, NspB, NspC and NspD are almost completely consistent between the 16S rDNA and ISR trees. The clustering of the organisms in subcluster NspA in the $16 \mathrm{~S}$ rDNA tree is also largely confirmed by the ISRbased phylogeny, although the position of Nitrosospira sp. B6 is uncertain. This isolate belongs to NspA in the 16S rDNA-based tree (Fig. 1a), while being more closely related to the NspC organisms in the ISR tree (Fig. 1b).

The statistical significance of the phylogenetic trees in Fig. 1 was tested by bootstrap analyses with 100 replicates (Fig. 2). The majority rule consensus trees (corresponding to the neighbour-joining trees in Fig. 1), with bootstrap values, are shown in Fig. 2. The bootstrap analysis of the 16S rDNA sequence data reveals some uncertainties, particularly concerning the NspA and NspC clusters (see legend to Fig. 2 for details). Still, all the nodes leading to discrepancies between the neighbour-joining tree in Fig. 1(a) and the majority rule consensus tree in Fig. 2(a) are supported by low bootstrap values and should not be considered significant. The discrepancies between the trees probably reflect the difficulties in performing phylogenetic analyses of highly similar DNA sequences, such as the AOB 16S rDNA sequences, and also the problems of comparing sequences with different evolutionary rates. Possibly, some features of the ISR tree reflect recent evolutionary events that are not yet reflected in the $16 \mathrm{~S}$ rDNA tree. The main topologies of the two trees based on the ISR sequence data (Figs $1 b$ and $2 b$ ) are the same, although some of the nodes separating the Nitrosospira clusters appear with low frequencies. Nodes appearing with low frequencies in the $16 \mathrm{~S}$ rDNA-based consensus tree (Fig. 2a) correspond to nodes with low bootstrap values in the ISR-based consensus tree (Fig. 2b).

\section{Comparison of the new 16S rDNA sequences with oligonucleotides assumed to be specific for the $16 \mathrm{~S}$ rRNA gene of $\beta$-proteobacterial AOB}

The match between previously published 16S rDNA sequences and oligonucleotides assumed to be specific for the AOB has been reviewed by Utåker \& Nes (1998). Since this review was published, some new AOB-specific oligonucleotides have been reported (Stephen et al., 1998). An alignment between the new 16S rDNA sequences and the published AOB-specific oligonucleotides was performed to check the match between the new 16S rDNA sequences and these oligonucleotides.

In general, the new sequences presented here do not alter the claimed specificity of the 31 AOB-specific oligonucleotides evaluated by Utåker \& Nes (1998). Comparison between the 16S rDNA sequences presented in this study and the 16S rDNA-specific oligonucleotides constructed by Stephen et al. (1998) show some discrepancies, however. The oligonucleotide named NspCL1_249, is not $100 \%$ complementary to any of the $3816 \mathrm{~S}$ rDNA sequences. The NspCL1_249 sequence is assumed to be specific for organisms in the 'Nitrosospira cluster 1' (cluster definitions by Stephen et al., 1996), from which no pure cultures of AOB are available. Consequently, the quality and biological significance of this oligonucleotide is more difficult to assess. The best match between the NspCL1_249 oligonucleotide and a 16S rDNA sequence from a pure culture is obtained with Nitrosomonas sp. Nm33 (two mismatches), while there are three or four mismatches with the other 37 sequences included in the present study. The specificity of the Nitrosomonas-specific oligonucleotides Nmo254 and Nmo254a is not convincing in distinguishing well between the Nitrosospira- and Nitrosomonas-like sequences. Unless very stringent hybridization conditions are used, it is likely that Nmo254 and Nmo254a will detect most $\beta$-subclass Proteobacteria. The same 
may be true for NmoCL6a_205 which has three mismatches with several Nitrosomonas sequences and with all Nitrosospira sequences. Most of the mismatches between these oligonucleotides and the $16 \mathrm{~S}$ rDNA sequences are found in or near the middle of the sequences, which might be problematic, especially if the oligonucleotides should be used for specific detection of certain groups of AOB.

\section{Conclusion}

In the present work information on the phylogeny of AOB based on the 16S rRNA genes and the 16S-23S rDNA ISRs has been obtained. Phylogenetic trees based on these two regions display high consistency regarding the relationships between the organisms included. Although the DNA-DNA homology values have not been determined for all the organisms studied here, the patterns shown are good indications that species affiliations of AOB based on DNA-DNA homologies are in accordance with the phylogenetic relations based on rDNA sequences. Species determination based on DNA-DNA hybridization is a technique that is the 'standard arbiter' for species designation (Murray et al., 1990; Stackebrandt \& Goebel, 1994), but the technique is laborious and demands relatively large amounts of cell material which are difficult (and sometimes impossible) to obtain with AOB. Although the species determination by DNA homology values is important, particularly for organisms that are closely related at the 16S rRNA gene level, the term 'rRNA species complex' (Stackebrandt \& Goebel, 1994) could be an applicable alternative. In our opinion, the data obtained here are compelling evidence that the $16 \mathrm{~S}$ rDNA, the $16 \mathrm{~S}-23 \mathrm{~S}$ rDNA ISR sequences and species affiliations reflect the same relationships between AOB, which is important information for future analyses of natural diversity of AOB.

Since the ISR and 16S rDNA sequences of AOB display consistent phylogenies, and since the ISR sequences show considerably higher variability than the $16 \mathrm{~S}$ rDNA sequences from the same organisms, the importance of the ISR for molecular ecology studies is clear. Alignment of the ISR sequences from the AOB revealed several regions that probably can be used as oligonucleotides specific for all or for certain subgroups of the AOB in the $\beta$-subclass of the Proteobacteria. In fact, the variability of ISR sequences from AOB might be so high that this region could be used in ecological applications. Thus, for assessment of natural populations of $\mathrm{AOB}$, possible specific oligonucleotides based on ISR sequences might be used in combination with specific oligonucleotides based on $16 \mathrm{~S}$ rDNA sequences.

\section{ACKNOWLEDGEMENTS}

The authors thank Dr Jenny Norton, Utah State University, for kindly providing the Nitrosospira isolates $24 \mathrm{C}$ and 39-19. This work was supported by grants from the Norwegian Research Council to J.B. U. and to A. A.

\section{REFERENCES}

Aakra, Å., Utåker, J. B. \& Nes, I. F. (1999a). RFLP of rRNA genes and sequencing of the $16 \mathrm{~S}-23 \mathrm{~S}$ rDNA intergenic spacer region of ammonia oxidizing bacteria: a phylogenetic approach. Int $J$ Syst Bacteriol 49, 123-130.

Aakra, Å., Utåker, J. B., Nes, I. F. \& Bakken, L. (1999b). An evaluated improvement of the extinction dilution method for isolation of ammonia-oxidizing bacteria. J Microbiol Methods 39, 23-31.

Aakra, Å., Hesselsøe, M. \& Bakken, L. R. (2000). Surface attachment of ammonia-oxidizing bacteria in soil. Microb Ecol 39, 222-235.

Acinas, S. G., Anton, J. \& Rodriguez-Valera, F. (1999). Diversity of free-living and attached bacteria in offshore Western Mediterranean waters as depicted by analysis of genes encoding $16 \mathrm{~S}$ rRNA. Appl Environ Microbiol 65, 514-522.

Barry, T., Colleran, G., Glennon, M., Dunican, L. K. \& Gannon, F. (1991). The $16 \mathrm{~S} / 23 \mathrm{~S}$ ribosomal spacer region as a target for DNA probes to identify eubacteria. PCR Methods Appl 1, 51-56.

Borneman, J. \& Triplett, E. W. (1997). Molecular microbial diversity in soils from eastern Amazonia: evidence for unusual microorganisms and microbial population shifts associated with deforestation. Appl Environ Microbiol 63, 2647-2653.

Brosius, J., Palmer, M. L., Kennedy, P. J. \& Noller, H. F. (1978). Complete nucleotide sequence of a $16 \mathrm{~S}$ ribosomal RNA gene from Escherichia coli. Proc Natl Acad Sci USA 75, 4801-4805.

Brosius, J., Dull, T. J. \& Noller, H. F. (1980). Complete nucleotide sequence of a 23S ribosomal RNA gene from Escherichia coli. Proc Natl Acad Sci US A 77, 201-204.

Edwards, U., Rogall, T., Blocker, H., Emde, M. \& Bottger, E. C. (1989). Isolation and direct complete nucleotide determination of entire genes. Characterization of a gene coding for $16 \mathrm{~S}$ ribosomal RNA. Nucleic Acids Res 17, 7843-7853.

Felsenstein, J. (1993). PHYLIP (Phylogeny Inference Package), 3.572c. Seattle: Department of Genetics, University of Washington.

Fox, G. E., Wisotzkey, J. D. \& Jurtshuk, P., Jr (1992). How close is close: 16S rRNA sequence identity may not be sufficient to guarantee species identity. Int J Syst Bacteriol 42, 166-170.

Garcia-Martinez, J., Acinas, S. G, Anton, A. I. \& Rodriguez-Valera, F. (1999). Use of the $16 \mathrm{~S}-23 \mathrm{~S}$ ribosomal genes spacer region in studies of prokaryotic diversity. J Microbiol Methods 36, 55-64.

Gürtler, V. \& Stanisich, V. A. (1996). New approaches to typing and identification of bacteria using the $16 \mathrm{~S}-23 \mathrm{~S}$ rDNA spacer region. Microbiology 142, 3-16.

Head, I. M., Hiorns, W. D., Embley, T. M., McCarthy, A. J. \& Saunders, J. R. (1993). The phylogeny of autotrophic ammoniaoxidizing bacteria as determined by analysis of $16 \mathrm{~S}$ ribosomal RNA gene sequences. J Gen Microbiol 139, 1147-1153.

Head, I. M., Hiorns, W. D., Embley, T. M., McCarthy, A. J. \& Saunders, J. R. (1995). Nitrosopira multiformis comb. nov. and Nitrosospira tenuis comb. nov. In Validation of the Publication of New Names and New Combinations Previously Effectively Published Outside the IJSB, List no. 54. Int J Syst Bacteriol 45, 619-620.

Jensen, M. A., Webster, J. A. \& Straus, N. (1993). Rapid identification of bacteria on the basis of polymerase chain reactionamplified ribosomal DNA spacer polymorphisms. Appl Environ Microbiol 59, 945-952. 
Jiang, Q. Q. \& Bakken, L. R. (1999). Comparison of Nitrosospira strains isolated from terrestrial environments. FEMS Microbiol Ecol 30, 171-186.

Jones, R. D., Morita, R. Y., Koops, H.-P. \& Watson, S. W. (1988). A new marine ammonium-oxidizing bacterium, Nitrosomonas cryotolerans sp. nov. Can J Microbiol 34, 1122-1128.

Koops, H.-P. \& Harms, H. (1985). Deoxyribonucleic acid homologies among 96 strains of ammonia-oxidizing bacteria. Arch Microbiol 141, 214-218.

Koops, H.-P., Böttcher, B., Möller, U. C., Pommerening-Röser, A. \& Stehr, G. (1991). Classification of eight new species of ammonia-oxidizing bacteria: Nitrosomonas communis sp. nov., Nitrosomonas ureae sp. nov., Nitrosomonas aestuarii sp. nov., Nitrosomonas marina sp. nov., Nitrosomonas nitrosa sp. nov., Nitrosomonas eutropha sp. nov., Nitrosomonas oligotropha sp. nov. and Nitrosomonas halophila sp. nov. J Gen Microbiol 137 , 1689-1699.

Kowalchuk, G. A., Stephen, J. R., de Boer, W., Prosser, J. I., Embley, T. M. \& Woldendorp, J. W. (1997). Analysis of ammoniaoxidizing bacteria of the $\beta$ subdivision of the class Proteobacteria in coastal sand dunes by denaturing gradient gel elctrophoresis and sequencing of PCR-amplified 16S ribosomal DNA fragments. Appl Environ Microbiol 63, 1489-1497.

Lane, D. J., Pace, B., Olsen, G. J., Stahl, D. A., Sogin, M. L. \& Pace, N. R. (1985). Rapid determination of $16 \mathrm{~S}$ ribosomal RNA sequences for phylogenetic analyses. Proc Natl Acad Sci US A 82, 6955-6959.

McCaig, A. E., Embley, T. M. \& Prosser, J. I. (1994). Molecular analysis of enrichment cultures of marine ammonia oxidisers. FEMS Microbiol Lett 120, 363-368.

Murray, R. G. E., Brenner, D. J., Colwell, R. R., deVos, P., Goodfellow, M., Grimont, P. A. D., Pfennig, N., Stackebrandt, E. \& Zavarzin, G. A. (1990). Report of the ad hoc committee on approaches to taxonomy within the Proteobacteria. Int J Syst Bacteriol 40, 213-215.

Nagpal, M. L., Fox, K. F. \& Fox, A. (1998). Utility of $16 \mathrm{~S}-23 \mathrm{~S}$ rRNA spacer region methodology: how similar are interspace regions within a genome and between strains for closely related organisms? J Microbiol Methods 33, 211-219.

Page, R. D. M. (1996). TreeView: An application to display phylogenetic trees on personal computers. Comput Appl Biosci 12, 357-358.

Pommerening-Röser, A., Rath, G. \& Koops, H.-P. (1996). Phylogenetic diversity within the genus Nitrosomonas. Syst Appl Microbiol 19, 344-351.
Purkhold, U., Pommerening-Roser, A., Juretschko, S., Schmid, M. C., Koops, H. P. \& Wagner, M. (2000). Phylogeny of all recognized species of ammonia oxidizers based on comparative $16 \mathrm{~S}$ rRNA and amo $A$ sequence analysis: implications for molecular diversity surveys. Appl Environ Microbiol 66, 53685382.

Robleto, E. A., Borneman, J. \& Triplett, E. W. (1998). Effects of bacterial antibiotic production on rhizosphere microbial communities from a culture-independent perspective. Appl Environ Microbiol 64, 5020-5022.

Stackebrandt, E. \& Charfreitag, O. (1990). Partial 16S rRNA primary structure of five Actinomyces species: phylogenetic implications and development of an Actinomyces israelii specific oligonucleotide probe. J Gen Microbiol 136, 37-43.

Stackebrandt, E. \& Goebel, B. M. (1994). Taxonomic note: a place for DNA-DNA reassociation and 16S rRNA sequence analysis in the present species definition in bacteriology. Int $J$ Syst Bacteriol 44, 846-849.

Stephen, J. R., McCaig, A. E., Smith, Z., Prosser, J. I. \& Embley, T. M. (1996). Molecular diversity of soil and marine 16S rRNA gene sequences related to $\beta$-subgroup ammonia-oxidizing bacteria. Appl Environ Microbiol 62, 4147-4154.

Stephen, J. R., Kowalchuk, G. A., Bruns, M. A. V., McCaig, A. E., Phillips, C. J., Embley, T. M. \& Prosser, J. I. (1998). Analysis of beta-subgroup proteobacterial ammonia oxidizer populations in soil by denaturing gradient gel electrophoresis analysis and hierarchical phylogenetic probing. Appl Environ Microbiol 64, 2958-2965.

Teske, A., Alm, E., Regan, J. M., Toze, S., Rittmann, B. E. \& Stahl, D. A. (1994). Evolutionary relationships among ammonia- and nitrite-oxidizing bacteria. J Bacteriol 176, 6623-6630.

Thompson, J. D., Higgins, D. G. \& Gibson, T. J. (1994). CLUSTAL $\mathrm{W}$ : Improving the sensitivity of progressive multiple sequence alignment through sequence weighting, positions-specific gap penalties and weight matrix choice. Nucleic Acids Res 22, $4673-4680$

Utåker, J. B. \& Nes, I. F. (1998). A qualitative evaluation of the published oligonucleotides specific for the 16S rDNA gene sequences of the ammonia-oxidizing bacteria. Syst Appl Microbiol 21, 72-88.

Utåker, J. B., Bakken, L., Jiang, Q. Q. \& Nes, I. F. (1995). Phylogenetic analysis of seven new isolates of ammoniaoxidizing bacteria based on 16S rRNA gene sequences. Syst Appl Microbiol 18, 549-559.

Weisburg, W. G., Barns, S. M., Pelletier, D. A. \& Lane, D. J. (1991). $16 \mathrm{~S}$ ribosomal DNA amplification for phylogenetic study. J Bacteriol 173, 697-703. 